\title{
Encouraging general practitioners to complete the four-year-old Healthy Kids Check and provide healthy eating and physical activity messages
}

\author{
A. Colin Bell, ${ }^{1}$ Elizabeth Campbell, ${ }^{2}$ J. Lynn Francis, ${ }^{3}$ John Wiggers ${ }^{1,2}$
}

\begin{abstract}
aking action on obesity is a priority of governments globally, ${ }^{1}$ and expanding primary health services to deliver or develop referral pathways to provide advice and support on weight loss, physical activity and healthy nutrition is an important component of comprehensive action. ${ }^{2}$

In this context, the Australian government introduced the Healthy Kids Check in July 2008 as a recommended preventive care action for all four-year-olds as part of Medicare, Australia's publically funded universal health insurance scheme. ${ }^{3}$ The check, which is initiated by a child's General Practitioner (GP) and/or Practice Nurse (PN) when parents present for their child's vaccinations includes mandatory checks of eyesight, hearing and oral health as well as assessment of weight. Provision of nutrition and physical activity advice to parents in line with clinical practice guidelines for the management of overweight and obesity in children is recommended. ${ }^{4,5}$ The check is provided for healthy rather than sick children and Medicare reimbursement ( $\$ 45$ in July 2008) for completing the check can be claimed by a GP or PN, addressing time and remuneration barriers to GP involvement in preventive healthcare. ${ }^{6}$

The potential for the HKC to make a significant contribution to the prevention and control of childhood overweight and obesity is based on a number of characteristics of general practice care provision. First, general practice provides access to a majority of children. In 2005-2006, 88\% of the Australian population visited a GP at least once, ${ }^{7}$ with
\end{abstract}

\begin{abstract}
Objective: To describe the impact of a training and support intervention to encourage completion of the Healthy Kids Check (HKC) by general practitioners (GP) or practice nurses (PN) and provision of brief advice on diet and physical activity.

Methods: The intervention (June 2008 to July 2010) was delivered by Divisions of General Practice (DGP) in the Hunter New England (HNE) region of NSW, Australia, to members in 300 practices. Intervention impact was evaluated using Medicare data on the number of HKCs completed and a post-intervention telephone survey of randomly selected parents in HNE and rest of NSW.

Results: Training reached $31 \%$ of GPs ( $n \sim 216 / 700)$ and $71 \%$ of PNs ( $n \sim 320 / 450) ; 31 \%$ of four-year-olds received a HKC in HNE compared to $15 \%$ in NSW; $27 \%$ of HNE parents $(n=162)$ reported a GP or PN had provided advice during their child's vaccinations visit compared to $15 \%$ of parents $(n=154)$ in NSW ( $p=0.002)$. There was no significant difference in proportion of children who had weight or height assessed (55.6\% in HNE and 54.6\% in NSW).

Conclusions: Boosting HKC claims and healthy eating and physical activity messages in general practice is feasible. More intensive strategies are required if obesity prevention and management benefits are to be achieved.

Implications: General practice is an important but under-utilised source of advice for parents and data for policy makers on childhood obesity in Australia.
\end{abstract}

Key words: general practice, brief advice, nutrition and physical activity, children, obesity prevention and management

an average visit frequency for children under 15 of about 3.5 visits per person per year. ${ }^{8}$ This enables GPs to provide brief advice to children and their parents on healthy eating and physical activity regardless of weight status. Second, GPs are seen as a trusted source of advice. ${ }^{9}$ Third, parents think GPs have an important role identifying children at risk of overweight and managing overweight and obesity, as do GPs themselves. ${ }^{10}$ A systematic review of primary care interventions to treat childhood overweight and obesity found evidence for the following intervention components: training for health professionals before intervention delivery; behaviour change options (including healthy diet, activity and sedentary behaviour); effecting behaviour change via a combination of counselling, education, written resources, support and motivation; and tailoring intensity according to whether behavioural, anthropometric or metabolic changes are the priority. ${ }^{11}$

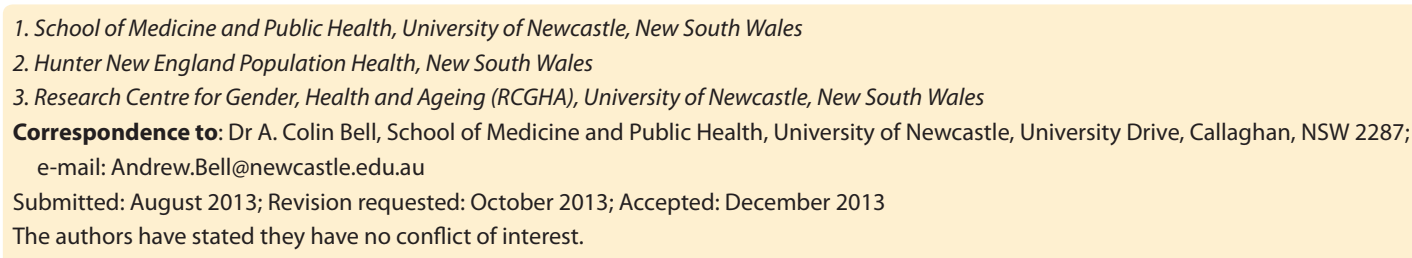


This paper describes the impact of an intervention designed to encourage GPs to complete the HKC and to provide messages on healthy eating and physical activity.

\section{Methods}

\section{Study design}

We used a post-test only quasi-experimental design. GPs and PNs were provided training and support over a two-year period. The outcome measures of interest were: the population rate of HKCs undertaken in the intervention region (HNE) compared to the state of NSW (including HNE), and parentreported GP or PN provision of healthy eating and physical activity advice during the HKC visit, assessed post-intervention in HNE and compared to NSW (excluding HNE). The study was funded by NSW Health and was in compliance with the Helsinki Declaration. Ethics approval was obtained from the Aboriginal Health and Medical Research Council (637/08) and the HNE Human Research Ethics Committee (HNEHREC 06/07/26/4.04).

\section{Study setting and sample \\ Practitioners}

The study was a component of a comprehensive child obesity prevention program in the HNE region of NSW, Australia (www.goodforkids.new.gov.au). The region is large $\left(130,000 \mathrm{~km}^{2}\right)$ with a demographically diverse population residing in metropolitan urban and suburban areas, regional centres, and rural and isolated remote communities. At the time of the study, five Divisions of General Practice (DGPs, now known as Medicare locals) provided support services across the HNE region to about 300 general practices, with more than 520 full-time equivalent general practitioners ( 700 practitioners), and at least 450 practice nurses. The number of practices within each DGP varied between 18 and 148 .

\section{Parents}

Self-report data on care provided in conjunction with immunisation was obtained from a cross sectional random sample of $(n=316)$ parents of children aged 4-6 years from the intervention region (HNE) and from the rest of NSW (excluding HNE) at the completion of the intervention in 2010. Data were collected via a computer assisted telephone interview.

\section{Intervention design}

Intervention strategies to train GPs and PNs in measuring weight and height as part of the HKC, and to support their completion of the check, were based on capacity building and health promotion theory and the strategies are summarised in Table 1.12-14 DGPs were contracted to provide training on weight and height assessment, body mass index calculation (BMl = weight $(\mathrm{kg})$ / height $\left(\mathrm{m}^{2}\right)$, charts were provided to practices for calculating children's BMI based on the Centers for Disease Control reference population, and on provision of brief advice on healthy eating and physical activity to all children and parents in a sensitive manner as per the clinical practice guidelines for the management of overweight and obesity in children. ${ }^{4}$ Flip charts and training materials were provided for the professional development sessions and practice visits. DGPs were also contracted to provide supportive practice visits (a minimum of one visit to $80 \%$ of practices) and regular communication (at least four newsletters/ year) to practices to reinforce training and encourage uptake of the HKC.

\section{Intervention delivery}

The DGPs were chosen to deliver the intervention as credible and recognised delivery agents. ${ }^{15}$ Service agreements with all five DGPs in HNE were put in place from July 2008 to June 2009 and included targets for the number of clinicians attending training and the number of practice visits. Three divisions covering $81 \%$ of all HNE general practices continued participating in the intervention for a further year (July 2009-June 2010). Endorsement for the intervention was provided by the HNE General Practice Partnership, a collaboration between DGPs and the HNE Local Health District.

\section{Comparison area}

Some training was available through GP NSW (www.gpnsw.com.au) to support implementation of the HKC throughout NSW during the intervention period and, from 2010, NSW Health offered free training provided by Karitane, a nongovernment organisation providing parents services (www.karitane.com.au), for PNs regarding implementation of the check. This subsequently became the Healthy Kids Check E-learning package. We were not able to quantify uptake of training during the intervention period but personal communication with staff involved suggest it was low. Also, a parent booklet produced by the Commonwealth Department of Health and Ageing was provided to parents in both the intervention and comparison areas.

\section{Data collection and measures}

Provision of training and support: On a six monthly basis, DGP representatives recorded details of professional development

\section{Table 1: Intervention strategies.}

\begin{tabular}{|c|c|}
\hline Strategy & Intervention (Practices) \\
\hline \multirow[t]{3}{*}{ Training } & $\begin{array}{l}\text { Accredited professional development session (weight and height assessment, BMI calculation, healthy } \\
\text { eating and physical activity advice, weight sensitivity) }\end{array}$ \\
\hline & DVD of professional development session \\
\hline & GPs and PNs reminded of medicare reimbursement at training and practice visits. \\
\hline
\end{tabular}

Practice support Aim was to reach $80 \%$ of practices with at least one visit and DGP specific targets were set for the proportion of GPs/PNs reached

Two divisions had additional targets to reach at least $50 \%$ practices with 2 or more visits

Practices could email or phone the DGP contact, plus all newsletter items contained toll-free number to Good for Kids program for further queries, or resource requests.

Education materials Good for Kids, Good for Life Waiting room poster (encourages asking about HKC).

Good for Kids, Good for Life Healthy Family checklist (a checklist for literate parents to score their healthy habits and plan small changes in family habits designed to be used in consultation or given to parent). This complemented the Commonwealth Resource Get Set 4 Life- Habits for healthy kids also provided at HKCS.

NHMRC guidelines on Management of Childhood Obesity, plus recent articles on practical application of guidelines.

BMI calculation tables.

Resources to give to children included Good for Kids Water bottles (some areas only), wristbands, stickers, temporary tattoos and tennis balls.

Information was included in clinician newsletters on the Good for Kids program, HKC, assessing children's BMI, sweetened drinks, fruit and vegies, snacks, physical activity, Aboriginal child health checks. 
events, practice visits undertaken and communication activities.

HKCs undertaken: Medicare item numbers identify services that attract rebates under the Medical Benefits Schedule of Medicare and items 709 (HKCs undertaken by GPs) and 10986 (HKCs undertaken by PNs) processed from July 2008 to December 2010 were accessed from the Medicare Australia website, ${ }^{16}$ for NSW (including HNE). HNE item numbers were obtained directly from DGPs because a change to the Medicare Benefits Schedule in April 2010 made it difficult to track item 709 online by individual DGPs.

Parent report of advice: Parents of children aged 4-6 years were asked whether, in the past two years, they had been with their child to a general practice for their four-year-old vaccination. Those who had attended were asked whether a GP or PN measured height or weight (yes both; no height only; no weight only; no neither; don't know) and talked with them or gave them tips about healthy eating or physical activity for their child (yes healthy eating only; yes physical activity only; yes both; no neither; don't know/can't remember). The survey also assessed sociodemographic characteristics.

\section{Analysis}

Descriptive statistics were used to describe the proportion of GPs and PNs trained and support visits conducted. To determine the proportion of four-year-olds who had received a HKC over the intervention period, we calculated the average number of HKC claims per year and divided this by the average estimated residential population of four-year-olds. ${ }^{17}$ Analyses of parent survey data were performed using SAS 9.2. Fisher exact tests were used to compare demographic characteristics (gender, age, ethnicity, rural/urban location and socioeconomic index for areas (SEIFA) based on postcode) and logistic regression was used to compare responses from HNE and NSW parents on care provided during the fouryear-old vaccination consultation, adjusting for SEIFA tertile. ${ }^{18,19}$

\section{Results}

\section{Provision of training and support}

During the intervention period, professional development sessions were provided to 216 ( 31\%) GPs and 320 ( 71\%) PNs. Fifty-two per cent of practices had one practice visit,
$9 \%$ had two visits and $29 \%$ had three or more visits. Only $10 \%$ of practices received no visits. Overall, $38 \%$ of practices had at least two visits. The number of general practice staff reached during the visits included 71 GPs ( 10\%), 134 PNs ( 30\%) and 83 practice managers (proportion reached unknown).

\section{HKCs undertaken}

Over the 21/2 years from July 2008 to Dec 2010, DGPs reported 2,762 claims for item 709 and 5,195 claims for item 10986 in HNE, or 3,183 claims/year. In NSW, there were 14,109 claims for item 709 and 21,441 claims for item 10986 in NSW or 14,220 claims/year. The average estimated residential population of fouryear-olds in HNE and NSW was 10,402 and 89,153 respectively. Based on these figures, the proportion of four-year-olds in HNE who received a HKC was low (3,183/10,402 31\%). However, it was almost double that observed for NSW as a whole (14,220/89,153 16\%). Moreover, HNE HKCs represented $20 \%$ of all checks completed by GPs and $24 \%$ of those completed by PNs in NSW. These proportions were higher than expected given that $~ 12 \%$ of all four-year-olds in NSW live in HNE.

\section{Parent report of advice}

A total of 1,618 parents of children 2-15 years completed the parent survey in MaySeptember 2010 (response rate 63\%). Of those, 471 were parents with children aged between four and six years at the time of the survey and 316 of those $(n=162$ HNE, $n=154$ NSW) or $67 \%$ reported attending a general practice consultation with their child for the four-year-old vaccination in the previous two years. Parent and child characteristics along with reported measurement of weight and height and provision of advice on healthy eating and physical activity are shown in Table 2.

There were no statistically significant differences between HNE and NSW in parent or child gender, age or ethnicity or in location. NSW parents were significantly more likely to be in the highest tertile for SEIFA ( $p=0.0001)$. Just over half ( $\sim 55 \%)$ of parents reported that their child had had their weight and height measured and after adjusting for differences in SEIFA, there were no statistically significant differences in the proportion of parents reporting measurement of their child's weight and height between HNE and NSW. However, HNE parents (27\%) were significantly more likely to report that a GP or PN had provided healthy eating and/or physical activity advice at the consultation than NSW parents (13\% $p=0.0005$ ).

\section{Discussion}

We found that HKC uptake was low ( $31 \%$ of all four-year-olds in HNE) but that uptake was higher in HNE compared to NSW, as was the provision of healthy eating and physical activity advice. No differences were observed between HNE and NSW in the proportion of children who had their weight and height measured.

We are not aware of other studies evaluating the effectiveness of a training and support intervention designed to enhance HKC uptake and in particular the components relevant to obesity prevention/management. However, comparisons of intervention intensity and effectiveness are possible with two studies of similar design..$^{20,21}$ The first was a trial of a primary care-based physical activity counselling intervention. ${ }^{20}$ Through awareness raising, training in physical activity counseling, practice visits, and the provision of pedometers, GPs ( $n=66$ from 23 practices) were encouraged to promote physical activity to their patients. Practice-level uptake was assessed by participation in practice visits. Ninety-one percent of practices accepted a visit and $58 \%$ of GPs participated. Resource

\begin{tabular}{|c|c|c|c|}
\hline Variable & $\begin{array}{l}\text { HNE } \\
(n=162)\end{array}$ & $\begin{array}{l}\text { NSW } \\
(n=154)\end{array}$ & $P$-Value \\
\hline \multicolumn{4}{|l|}{ Parent characteristics } \\
\hline Female (\%) & 84 & 83 & 0.88 \\
\hline Age (mean) & 37.3 & 37.3 & 0.98 \\
\hline Aboriginality (\%) & 2.5 & 0.6 & 0.37 \\
\hline Urban (\%) & 71.0 & 76.3 & 0.31 \\
\hline Highest SEIFA tertile* & 14.8 & 45.4 & 0.0001 \\
\hline \multicolumn{4}{|l|}{ Child characteristics } \\
\hline Female (\%) & 47 & 51 & 0.50 \\
\hline Age (mean) & 4.9 & 5.0 & 0.25 \\
\hline Aboriginality (\%) & 3.1 & 2.6 & 1.0 \\
\hline $\begin{array}{l}\text { Doctor or practice } \\
\text { nurse assessed weight } \\
\text { and height (\%) }\end{array}$ & $55.6 \%$ & $54.6 \%$ & $0.82^{* *}$ \\
\hline $\begin{array}{l}\text { Doctor or practice } \\
\text { nurse provided healthy } \\
\text { eating or physical } \\
\text { activity advice (\%) }\end{array}$ & $27.2 \%$ & $12.9 \%$ & $0.0005^{* *}$ \\
\hline
\end{tabular}


use was high and there was an increase from $23.4 \%$ to $27.1 \%$ in the proportion of community members who reported receiving physical activity advice from their GP compared to a decrease (23.3\% to $20.6 \%$ ) in the comparison community. The second study, a training-based intervention with 18 primary care practices in Utah, US, increased assessment of paediatric BMI (from 55\% to $97 \%$ of patients) and provision of prevention messages from 11 (55\%) to 18 (100\%) practices. $^{21}$

These studies show higher uptake and similar or higher effectiveness to ours, suggesting our intervention strategies could have been more intensive. Indeed, only 3/5 DGPs participated over the full intervention period and less than a third of eligible GPs were trained. Also, a reliance on practice visits limited the amount of practice support because clinicians did not prioritize visits, and/or they involved too much travel for DGP staff. It should be noted that our intervention was conducted on a much larger scale than these comparison studies ( 300 practices compared to 23 and 18 respectively) and resources available to deliver the intervention were stretched. A greater investment in developing relationships with DGPs and practices, ${ }^{22}$ and the use of more effective techniques for motivation enhancement may also have helped. ${ }^{11,23}$ Reviews of interventions within general practice indicate that multiple strategies are more effective than single strategies and that education alone is not sufficient to achieve change. ${ }^{24,25}$

While low intervention intensity offers one explanation for low HKC uptake, other explanations include implementation barriers and/or reporting difficulties. ${ }^{26}$ Low uptake of the HKC has been reported previously. ${ }^{27}$ Medicare data collected over the two years from the introduction of the program to June 2010 show 81,463 completed HKCs claims (40,731 claims/year) for about 260,000 four-year-olds nationally ( $16 \%$ receiving a HKC each year). In our study, the Division representatives responsible for implementing the intervention reported that clinicians indicated difficulty getting through all components of the HKC in a timely manner, a low level of reimbursement for the work involved, difficulty knowing how to manage a child if their BMI assessment indicated they were at risk, the absence of specialist referral options, lack of skill in providing dietary advice, and the cost to parents of follow-up appointments, especially if a child was not at high risk.

One way to increase HKC uptake would be to include only those components that are supported by evidence (using BMI for assessing children's weight status is considered useful, but controversial because of limited treatment options). ${ }^{28,29}$ This would shorten the HKC and help address time and reimbursement related barriers. In keeping with the higher engagement of PNs with the training and their greater completion rates compared to GPs, it may also be beneficial to allocate the more time-consuming aspects of the check to nurses where they are available. Data from Division representatives in our study indicated that the intervention had helped build PNs awareness of and confidence assessing childhood obesity. Referral options for specialist follow-up care remain a challenge in Australia, although parent-education programs have been shown to be effective for changing the behaviours and weight status of overweight and obese primary school-aged children, ${ }^{30,31}$ and trials of programs for preschool children are under way. ${ }^{32}$

Several limitations should be considered when interpreting these findings. It is likely that we underestimated claims in HNE. Data on item 709 were not available from one DGP and data on item 10986 were not available from another so uptake of the HKC check in HNE may be better than shown. Limitations of the study design mean we cannot eliminate other explanations for the differences observed between HNE and NSW in HKC claims and parent-reported advice. For example, it is possible that there were more PNs available to complete the checks in HNE compared to NSW. We did not measure children's BMI and it is possible that higher BMIs account, in part, for the higher completions in HNE. However, this is unlikely as our surveys of children (kindergarten to year 4) at the start of the Good for Kids program showed a prevalence of overweight and obesity (21.6\% in 2007) in HNE children that was similar to that for children across the state ( $22 \%$ in 2004 , data not shown). We were also reliant on estimates of the resident population of four-year-olds, reducing the precision of our estimates. More rigorous evaluation is warranted.

\section{Conclusion}

Our findings suggest that boosting Medicare HKC claims and the provision of messages on healthy eating and physical activity is feasible. Evaluation of more intensive interventions is needed to demonstrate effectiveness. General practice is an important but under-utilised source of individual level information and advice for parents but as a stand-alone activity, primary care surveillance and intervention for childhood overweight and obesity is considered expensive and ineffective. ${ }^{33}$ What is different about the HKC approach is that it reduces costs by integrating BMI with other assessments. An intervention model where primary care clinicians assess BMI, motivate behaviour change at the HKC and refer children on to community-based parent-education programs may be more effective. ${ }^{11}$

\section{Acknowledgements}

We acknowledge the health professionals and parents who participated and the support of the Hunter New England Divisions of General Practice and NSW Health. Funded by the NSW Ministry of Health.

\section{References}

1. Gortmaker SL, Swinburn BA, Levy D, Carter R, Mabry PL, Finegood DT, et al. Changing the future of obesity: science, policy, and action. Lancet. 2011;378(9793): 838-47.

2. National Preventative Health Taskforce. Australia: The Healthiest Countryby 2020-National Preventative Health Strategy - Overview. Canberra (AUST): Government of Australia; 2009.

3. Department of Health and Ageing. Medicare Healthy Kids Check (MBSItems 709 and 711). Fact Sheet. Canberra (AUST): Government of Australia; 2008.

4. National Health and Medical Research Council.Clinical Practice Guidelines for the Management of Overweight and Obesity in Children and Adolescents. Canberra (AUST): Government of Australia; 2003.

5. Alexander K, Mazza D. How to perform a'Healthy Kids Check. Aust Fam Physician. 2010;39(10):761-5.

6. Waters EB, Haby MM, Wake M, Salmon LA. Public health and preventive healthcare in children:Current practices ofVictorian GPs and barriers to participation. Med JAust. 2000;173(2):68-71.

7. Knox SA, Harrison CM, Britt HC, Henderson JV. Estimating prevalence of common chronic morbidities in Australia. Med J Aust. 2008;189(2):66-70.

8. Charles J, Britt H, Harrison C. 2009. General practice workforce and workload. In: Britt H and Miller GC, editors. General Practice in Australia, Health Priorities and Policies 1998 to 2008. General Practice Series No. 24. Canberra (AUST): Australian Institute of Health and Welfare; 2009.

9. Hardie EA, Critchley CR. Public perceptions of Australia's doctors, hospitals and health care systems. Med J Aust. 2008;189:210-14. 
10. Pagnini D, King L, Booth S, Wilkenfeld R, Booth M. The weight of opinion on childhood obesity: Recognizing complexity and supporting collaborative action. Int $\mathrm{J}$ Pediatr Obes. 2009;4(4):233-41.

11. Sargent GM, Pilotto LS, Baur LA. Components of primary care interventions to treat childhood overweight and obesity: A systematic review of effect. Obes Rev. 2011;12(5):e219-35. doi: 10.1111/j.1467789x.2010.00777x.

12. NSW Health Department. A Framework for Building Capacity to Improve Health. Gladesville (AUST): Better Health Care Centre; 2001.

13. Bartholomew LK, Parcel GS, Kok G, Gottlieb NH. Intervention-mapping: Designing Theory and EvidenceBased Health Promotion Programs. Mountain View (CA): Mayfield; 2001.

14. Rogers EM. Diffusion of Innovations. 5th ed. New York (NY): Free Press; 2003.

15. Moretti C, Kalucy E, Hordacre AL, Howard S. South Australian Divisions of General Practice supporting diabetes care: Insights from reporting data. Aust J Prim Health. 2010;16(1):60-5.

16. Department of Health. Telehealth Statistics. Canberra (AUST): Government of Australia; 2013 [cited $2011 \mathrm{Sep}$ 13]. Available from: https://www.medicareaustralia. gov.au/statistics/mbs_item.shtml

17. Hunter New England Population Health, Hunter New England Health, Hunter New England Area Health Service. Health in Hunter New England Demography eResource [Internet]. Hunter New England (AUST): HNEPH; 2010 [cited 2011 Sep 12]. Available from:http:/ www2.hnehealth.nsw.gov.au/HNEPH/HHNE/dem/ demNSWPoppyr.htm

18. Australian Bureau of Statistics. 2033055 001.-- Census of Population and Housing: Socio-Economic Indexes for Areas (SEIFA), Australia-- Data Only, 2006. Canberra (AUST): ABS; 2008 [cited 2010 Feb 22]. Available from: http://www.abs.gov.au/AUSSTATS/abs@.nsf/DetailsPa ge/2033.0.55.0012006?OpenDocument
19. Information and Research Branch. Measuring Remoteness Accessibility/Remoteness Index of Australia (ARIA). Rev 2001 Occasional Papers. Canberra (AUST): Commonwealth Department of Health and Aged Care; 2001.

20. Eakin EG, Brown WJ, Marshall AL, Mummery K, Larsen E. Physical activity promotion in primary care: Bridging the gap between research and practice. Am J Prev Med. 2004;27(4):297-303.

21. Young PC, DeBry S, Jackson WD, et al. Improving the prevention, early recognition, and treatment of pediatric obesity by primary care physicians. Clin Pediatr. 2010;49(10):964-9.

22. Sims J, Huang N, Pietsch J, Naccarella L. The Victorian Active Script Program: Promising signs for GPs, population health and the promotion of physical activity. Br JSports Med. 2004;38:19-25.

23. Rubak S, Sandboek A, Lauritzen T, Christensen B. Motivational interviewing: A systematic review and meta-analysis. Br J Gen Pract. 2005;55:305-12.

24. Jamtvedt G, Young JM, Kristoffersen DT, O'Brien MA, Oxman AD. Audit and feedback: effects on professional practice and health care outcomes (Cochrane Review). In: The Cochrane Database of Systematic Reviews; Issue 2, 2006. Chichester (UK):Wiley; 2006.

25. Forsetlund L, Bjørndal A, Rashidian A, Jamtvedt $\mathrm{G}$, O'Brien MA, Wolf $F$, et al. Continuing education meetings and workshops: Effects on professional practice and health care outcomes (Cochrane Review). In: The Cochrane Database of Systematic Reviews; Issue 2, 2009. Chichester (UK):Wiley; 2009.

26. Jones KM, Dixon ME, Falkingham L, Piteman L, Dixon JB. Barriers to recruitment of professionals into a general practice childhood obesity program. Aust JPrim Health. 2011;17(2):156-61.
27. Russell L. Gillard's plans for compulsory child health checks slammed. Crikey. 2010 August.

28. Alexander K, Mazza D. The Healthy Kids Check - is it evidence based? Med J Aust. 2010;192:207-10.

29. Oberklaid F, Wake M, Harris C, et al. Child Health Screening and Surveillance: A Critical Review of the Evidence. Melbourne (AUST): National Health and Medical Research Council; 2002 [cited 2014 Mar 31]. Available from: http://www.nhmrc.gov.au/_files nhmrc/file/publications/synopses/ch42.pdf

30. Okely AD, Collins CE, Morgan PJ, et al. Multi-site randomized controlled trial of a child-centered physical activity program, a parent-centered dietarymodification program, or both in overweight children The HIKCUPS study. J Pediatr. 2010;157(3):388-94.

31. Burrows $\mathrm{T}$, Janet $\mathrm{WM}$, Collins CE. Long term changes in food consumption trends in overweight children enrolled in the Hikcups intervention. J Pediatr Gastroenterol Nutr. 2011;53(5):543-7.

32. Skouteris $\mathrm{H}$ McCabe $M$, Swinburn B. Hill B. Healthy eating and obesity prevention for preschooler: A randomised control trial. BMC Public Health. 2010;10:220.

33. Wake M, Baur LA Gerner B, et al. Outcomes and costs of primary care surveillance and intervention for overweight or obese children:The LEAP 2 randomised controlled trial.BrMedJ.2009;339:b3308. doi:10.1136/ bmj.b3308 